\title{
Truscott's Claims in Giving Corrective Feedback: Does It Matter in EFL Writing Context?
}

\author{
Hussein Meihami \\ Department of English Teaching, Ghorveh Branch, Islamic Azad University, Ghorveh, Iran
}

E-mail address: hussein.meihami@yahoo.com

\begin{abstract}
Giving Corrective Feedback in students' writings has got the years. The question of whether to give CF to students or not to do so In this research three Truscott's claims on giving CF were inves gate EFL stud ats' writing. For the purpose of this investigation Direct Feedback has been us draw conclusion on Truscott's claims. These claims are: (a) correction may have value fo non-grammatic cors but not for errors in grammar; (b) students are inclined to avoid more comp ex constructions due to error correction; and (c) the time spent on CF may be more wisely spent on ditional writi g practice to improve writing ability. The obtained results indicated that giving CF to s 'ents' gran matical errors has a significant result on their accuracy improvement. The research also a students don't tend to avoid Complex Structures due to the CF provided on tructures. And finally it indicated that in a class without any provided $\mathrm{CF}$ and just with doing ex cise subject the accuracy of students decrease during a writing program.
\end{abstract}

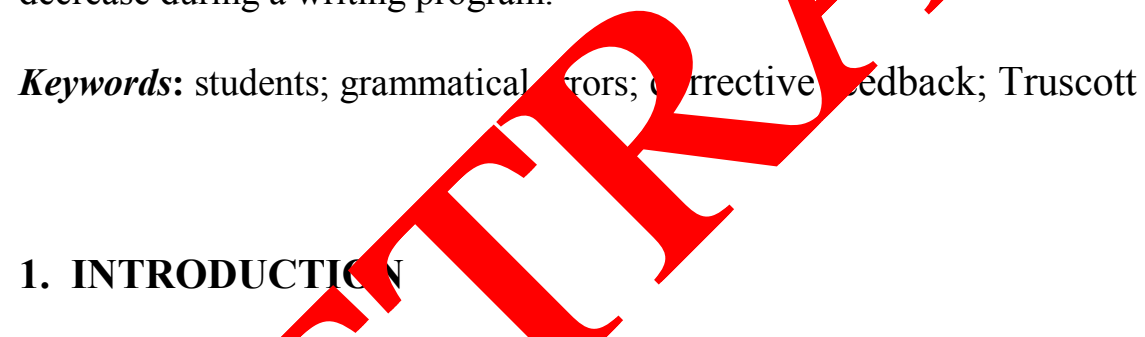

Correct e feeg ack (CF) probably the most widely used feedback in second language (L2) classroo (V/mbeu ingen, De Jong, and Kuiken; 2011). On the way round, however, as Truscott clà d err correction is necessarily ineffective and potentially harmful (Trus cou 1996). 1900 s to 2000s, he frequently presented objections with respect to th e fF in L2 writing classes (Truscott, 1996, 1999, 2004, 2007). Truscott's (1996) state is ineffective depends on both practical and theoretical arguments. His practica ubts concern to teachers' capacities in providing adequate and consistent feedback and to leary 's' ability and willingness to use the feedback effectively. His theoretical argument grounds on the claim that CF overlooks important insights from second language acquisition (SLA) theories, including (a) the gradual and complex nature of inter language development, which stands in stark contrast to error correction as a simple transfer of information; (b) the impossibility for any single form of $\mathrm{CF}$ to be effective across the very differently acquired domains of morphology, syntax, and lexis, particularly with respect to grammatical features that are "integral parts of a complex system" (Truscott, 2007, p. 258) and that would be heedless to change; (c) the likelihood that any proven advantages might be at least related to 
the development of explicit declarative knowledge (e.g. DeKeyser, 2003; Ellis, 2004), but never implicit procedural knowledge, which is all important for acquisition; thus, CF would promote "pseudo learning" or at best self-editing and revision skills, without supporting true accuracy development; and (d) the impracticality of preparing CF to each learner's current level of L2 development, in Pienemann's ( 1998) sense of learner readiness, given that results in this area to date are incomplete and not enough to be useful for teaching practice. In addition to arguing that error correction is ineffective, Truscott $(1996,2004$, and 2007) stated that correcting students' writing might be also counterproductive. One of his arguments was that teachers run the risk of making their students avoid more complex structures whan they emphasize learners' errors by providing CF. Truscott logic was that it is the imme alate go f error correction to make learners aware of the errors they committed and that is awarenc creates a motivation for students to avoid the corrected constructions in to e writir (Truscott, 2007). Second, Truscott $(1996,2004)$ claimed that CF is waste on re nd suggested that the energy spent on dealing with corrections-both by tea ers an tuden. could be allocated more ability to alter native activities, such as addition? wh practice

According to what has been mentioned, Truscott (1996) onvened dese cion of CF from L2 writing classes, until its usefulness had been proven os pirical re ch (Truscott, 1999, 2004, 2007). Although Ferris $(1999,2002$, and 2004) ade a nd for the use of written $\mathrm{CF}$ and argued that Truscott's conclusions were hasty smagreed $\mathrm{i}$ - sidence from welldesigned studies was necessary before any stable conclusions could be drawn about the effectiveness or ineffectiveness of error correction.

Framed within a cognitive perspective of $L 2$ a visition, $t$ le present study investigates on the effects of direct CF in an EFL situation to sur cott's claims. For this purpose three control groups and three treatment grou been used, which involve pretest, immediate ost obu, d delayed posttest has been involved in the study.

\section{1. Review of Literature}

The review of the evrous $\mathrm{T}_{\mathrm{V}}$ in Corrective Feedback has indicated that there is an increasing interest in 1 research field and it shows that the subject has found the center of current res arche For this teason, the review of literature of the current study has been divided in our parts he first part is discussing the researches that showed the effectiveness 1 Wit $n$ CF, the cond part is all about the relative effectiveness of Direct and Indirect $\mathrm{CF}$, thir part unraveling the $\mathrm{CF}$ researches in relation with different error types, and the fourth $\mathrm{p}$, is conf ring about the harmful part of giving $\mathrm{CF}$ effect.

\section{Th effectiveness of Witten CF}

'V empmical work on the effects of CF on L2 learners' writing can be categorized in two way set of studies that focused on the role of CF during the revision process and a second gro ap of investigations that set out to answer the question of whether correction produces a learning effect when new pieces of writing are inspected. The revision studies showed that language students were able to improve the accuracy of a particular piece of writing, based on the feedback provided (e.g., Ashwell, 2000; Fathman \& Whalley, 1990; Ferris, 1997; Ferris \& Roberts, 2001). These results thus showed that CF is a useful editing tool. However, as Truscott and Hsu (2008) have rightly argued, these results do not constitute evidence of learning, as only two versions of the same draft were compared. It thus remained unclear if students' success in using the feedback during revision would subsequently lead to 
acquisition of the corrected forms. One might also think that practice with autonomous selfediting of texts might be a better use of instructional time, if CF is really only beneficial as an editing tool. If one believes that editing is the only source of benefit of $\mathrm{CF}$, teachers might simply spend more instructional time in class encouraging the honing of self-editing skills.

The recognition that a focus on grammar learning benefits rather than on revision skills is needed has led the way into a growing body of tightly controlled investigations that has begun to explore the long term effects of CF on L2 writing by comparing learners' accuracy performance on pretests and (delayed) posttests. Following the methodology of oral feedback research (e.g., Ellis, Loewen, \& Erlam, 2006; Lyster, 2004), the majority of these resanchers (e.g., Bitchener, 2008; Bitchener \& Knoch, 2008, 2009, 2010a, 2010b; Ellis, Sheer, 1Muran i, \& Takashima, 2008; Sheen, 2007, 2010) have chosen to investigate the eff of focus correction, whereby CF only targets one persistently problematic error tye at ime (e. errors in the use of English articles).

The logic behind this focused approach is that learners might more rely to otice and understand corrections when just one feature is targeted (Elli et .008), p ticularly considering a limited processing capacity model of L2 acquisi on (Bitch or, $20 \mathrm{J8}$; Sheen, 2007). The extant findings thus far consistently point at strop s durable p ave effects of focused CF on learners' accuracy development (Xu, 2009

By comparison, evidence on the language learn ontial ocused $\mathrm{CF}$, which involves comprehensive correction of every error in students' writing is scarce. As far as it concerns, only four studies have investigated whe er compreh/nsive CF yields a learning effect. Two of them (Truscott \& Hsu, 2008; W Beuning in et al., 2008) compared comprehensive CF to no CF groups, where the othe \& Moldawa, 2009) included a focused and a group in their design.

Ellis et al. (2008) found accuracy gains or both their focused and comprehensive CF groups and thus concluded bo an a equally effective. However, some methodological weaknesses of the study hay en $\mathrm{d}$ scussed by Xu (2009) and, as the authors themselves acknowledged, students in fo a d or oup received more feedback on the target feature (i.e., English articles) th students e comprehensive CF group. Sheen et al. (2009), on the other hand, found th foo approag to be more helpful than provision of comprehensive feedback when bo hare co red to the control group. However, the authors pointed out that the correction ceived by the Inprehensive CF group was rather unsystematic in nature; although so erro were corrected, others were ignored. It is conceivable that this unsystematic of corre ing negatively influenced the effect of comprehensive CF in this study. evidu on potentially differential value of focused versus comprehensive CF wor a be ost wely ne, not only because of the discrepant results reviewed here but also bec. th that bo night be valuable feedback methodologies indifferent ways.

Ho 1 , the argument of the importance of producing more evidence about the singular contribution of unfocused or comprehensive CF on the accuracy of new pieces of writing is showing considerable significance. For one, and notwithstanding the important contribution of the focused CF work to the error correction debate, the implications that can be drawn from focused CF studies so far are rather limited, because the targeted linguistic features (i.e., English articles) are typically selected for maximal simplicity (Ferris, 2010; Truscott, 2010). $\mathrm{Xu}(2009)$ also noted that such a clear focus on just one or two grammatical structures may lead students to consciously monitor the use of that target feature when performing on the posttest(s). 


\section{1. 2. The Relative Effectiveness of Direct and Indirect $C F$}

Corrective feedback researchers have not only shown interest in the question of whether correction should be comprehensive or selective in nature. Many studies have also addressed "how" questions, exploring the relative effectiveness of different ways to deliver CF, or CF types. Most of these studies have categorized their CF methodologies as either direct or indirect (Van Beuningen et al, 2011). Whereas direct CF consists of an indication of the error and provision of the corresponding correct L2 form, indirect CF only indicates that an error has been made.

Indirect correction methods can take different forms that vary in their explici underlining of errors, coding of errors). What they share in common is that istead or teacher providing the target form, it is left to the learner to correct his/her ow arrors (V) Beuningen et al, 2011).

Clear empirical evidence on the differential effects of direct and ir direct $F F$ on $v$ acy development is lacking, as research on the issue has produced con ersines ts some researchers have found no differences between the two CF types \& Shortreed, 1986), others have reported an advantage for ind CF (Fen 20 56 ; Lalande, 1982), and yet others have found direct correction to be $m$, t en ive in $t h$ ir comparisons (Bitchener \& Knoch, 2010b; Chandler, 2003; Van Be Men è 2008). Problems of interpretation make these contradictory results, horever. Some or se studies were not designed to compare the two CF methodologies, an in other studies, the using of direct and indirect $\mathrm{CF}$ as distinct treatments was not rigorou nough. Ad ditionally, caution must be exercised when results are proclaimed on descriptive $1_{1 \text { ts }}$ vers is statistical significance tests and on comparisons against the other treatm versus thun trol group (Van Beuningen et al, 2011).

Bitchener and Knoch (2010b) reported a statist ally significance difference between direct and indirect $\mathrm{CF}$, found the a to $b$ in favor of the direct approach. However, the findings between the two studie are ny directly omparable, as the former investigated (direct and indirect) comprehensive Cr or inestigated (direct and indirect) focused CF.

\section{1. 3. CF and Differ Types of $\mathrm{E}$}

Truscott (20n expla that his case against CF (Truscott, 1996, 1999) was actually a case against gr mmar correctio 4 claimed that syntactic errors in particular might not be amenable to rrectic because they are integral parts of a complex system that-in Truscott's view-is imper, te to $C$ (Van Beuningen et al, 2011). He further more suggested that morpho ical te. es ar - evenly unlikely to take advantage from CF because their acquisition not nly a ends on understanding of form but also of meaning and use in relation to other wo. and artions of the language system.

Scott(ZV01, 2007 as cited in Van Beuningen et al, 2011) concluded that if CF has any value for development, this could only be true for "errors that involve simple problems in relatively c.screte items" (Truscott, 2001, p. 94)-such as spelling errors-and not for errors in grammar.

A number of studies explored the effects of CF on separate error types, and all reported differing levels of improvement for different types of errors (e.g. , Bitchener, Young, \& Cameron, 2005; Ferris, 2006; Ferris \& Roberts, 2001; Frantzen, 1995; Lalande, 1982; Sheppard, 1992). Ferris (2006), for instance, differentiated among five major error categories: verb errors, noun errors, article errors, lexical errors, and sentence errors. 
She found that students receiving CF only experienced a significant reduction from pretest to posttest in verb errors. Lalande (1982) distinguished 12 error types and observed that correction only led to a significant decrease in orthographical errors. Bitchener et al. (2005) investigated how focused CF impacted learners' accuracy development on three target structures and found that CF had a greater effect on the accuracy of past simple tense and articles than on the correct usage of prepositions. None of these studies, however, could test Truscott's claim that grammar correction is ineffective, because they were not set out by design to investigate whether $\mathrm{CF}$ is more advantageous for non-grammatical error types than for errors in grammar (Van Beuningen et al, 2011).

\section{1. 4. The Harmful Part of Giving CF}

Truscott has argued not only that CF is ineffective but also that it has arast harmf 1 side effects. One is simplified writing, based on the assumption that $\mathrm{CF}$ ncou ages lo o avoid situations in which they make errors (Van Beuningen et al, 2011, fact, rus th 2004, 2007) has argued that accuracy gains found in earlier correc st. s mig) well be attributable to such avoidance and simplified writing instead of

His suggestions are in line with limited capacity mod s ol ention $t h$, also predict a tradeoff between accuracy and complexity (e.g., Skeha 998). thin these models, L2 performance is expected to become more complex y nen learners aro Mlling to experiment with the target language. A focus on accuracy, on th other hand, "is seen to reflect a greater degree of conservatism" in which learners will try "t chieve gre ter control over more stable elements" while avoiding extending their L2 reperton "kehan $x$ Foster, 2001, p. 191).

Few studies have investigated the imp of writter on linguistic complexity, and, in our opinion, studies that did (Chandler, 200 al, 1986; Sheppard, 1992) could not come to any warranted conclusions. Shepparc $(1,92)$, or example, reported a negative effect of CF on the structural complex learne s writing, but in fact his finding was nonsignificant. Robb et al. (1986 found that CF ad a significant positive effect on written complexity, but they did notno foup without Corrective Feedback.

The same holds for nandle T03), who did not find any effect of CF on the complexity of students' writing. Aditional p $\mathrm{em}$ with the latter study is that Chandler based her conclusion on holist ratin f text quality. In our view, however, the fact that holistic ratings did not change $a$ not neco rily prove that the linguistic complexity of learners' writing did not chang either

The so d barmfu side effect of CF identified by Truscott $(1996,2004)$ was the diversion of tim nd ene sy away from more productive aspects of writing instruction, such as sh ting p ic (Van Beuningen et al, 2011). The only study that has directly tested thi laim $y$ compa ing the effects of CF to those of writing practice is an investigation by Shee. Their results opposed Truscott's claim by showing that learners did not benefit from writing practice than from $\mathrm{CF}$.

\section{METHODOLOGY}

\section{1. Research Questions}

As it was stated earlier Truscott has three claims on giving CF to student's witting that were mentioned as follow:

(A) Correction may have value for non-grammatical errors but not for grammatical errors 
(B) Students are inclined to avoid more complex constructions due to CF

(C) The time spent on CF may be wisely spent on additional writing practice to improve writing ability

Based on these claims, this research has been investigating on the following three research questions:

(A) Does using CF for EFL students in their writing improve their grammatical accuracy?

(B) Does giving CF to EFL students in their writing avoid them to use complex constructions? (C) Can the time spend on CF improve writing if wisely spent on additional y nting
practice?

\section{2. Participant}

In the February the first, 100 advanced students in English all an range from 16 to 20 were chosen to participate in this experimental resea English Program in Academic Language Center Institute. Ac ding to th ric Placement Test which had been given to the students, the exact proficie cy 1 of them as cleared. To instruct students, five English teachers were chosen to w with policy of this research study. In the registration stage, students were inform a that in winter mester writing skills had got an extended attention. The course took two onths and students attended 18 sessions, and two sessions in each week. The 100 selected stuc ts were div ded into five classes in each 20 students were attending. These five classes were igned t investigate Truscott's three claims in giving CF to EFL students' writin The total pus of the current research was to investigate these claims in EFL situation.

\section{3. Materials}

In this research a pretes med ite postte $l$, delayed posttest was run. In so doing, there needed three piece of writ is ung these resenes was based fundamentally on Truscott's claims. For th first clan Correction may have value for non-grammatical errors but not for grammati al rs, the co, ct use of verb pattern after model verbs, so students were required to yom a par of 200 words about the next summer trip, where will they want to go? Ap a what will the ant to do? The next claims: Students are inclined to avoid more compl const ctions due to $\mathrm{CF}$ and for investigating this claim, students first were under instruct. Comp and Sentences in English and then students were required to use this str re in wring about a memory. According to this claim of Truscott students avo the mplex s, cures and by using compound sentence structures we wanted to test this char For hic clain, during the pretest and immediate post test students were under feedback in con una semences but this instruction were stopped during the immediate posttest and delayed test for investigating the impact of CF on whether or not avoid students to use complex st actures when they were given CF. The third claim: The time spend on CF may be wisely spent on additional writing practice to improve writing ability students in one of chosen classes were just under doing exercises in correct verb pattern after model verbs without any $\mathrm{CF}$ in verb pattern after model verbs and then they were compared with the first class, the class which was given $\mathrm{CF}$ in correct verb pattern after model verbs to see the aspects of this claim. 


\section{4. Procedure}

After 100 students were enrolled in Winter English Program, they were divided into five classes to survey Truscott's claims. For the reason of clear categorization, the procedure part was divided into three parts.

\section{4. 1. Claim One}

Correction may have value for non-grammatical errors but not for grammatical errors: 40 out of 100 students were divided into two classes. Class A were going under givin $C F$ in correct verb patterns after model verbs and Class B without giving CF in verb ratterns model verbs. for so doing, in the second session the pretest was held and in th third sessi the students' writings were backed to them and in 40 minutes the instructorwas ing CF correct verb patterns after model verbs and afterward the immediate postte st was helc sho.d be stated that when students were enrolling they had been informed of ${ }^{1}$ fact $t$ in the cond session they were going to write their first writing as a kind of tes

During the second week, immediate posttest, and the eigb i week, $\mathrm{h}$. elay d posttest, the instructor was giving No CF on correct verb patterns af endel verbs Class B the procedure was the same except for the $\mathrm{CF}$ giving. In Class there No $\mathrm{CF}$ in correct verb patterns after model verbs for students so after their fy or ting in session in the third session the instructor of the class returned back y thout any CF and he immediate posttest was held. There was also delayed posttest was held

\section{4. 2. Claim Two}

Students are inclined to avoid more col plow tructions due to giving CF: another 40 out of 100 students were divided into; Class $\mathrm{C}$ ro vides CF in complex structures and Class D without giving $\mathrm{CF}$ in complex stry $\mathrm{s}$. For th ting this claim English Compound Sentences was instructed in both $C$ and $D$ Class . Compo Md sentences of English as the name speaks for itself are kind of Englis so no mbined two independent sentences. They are always hard for students $\mathrm{o}$ use the hecause of the complexity involved. In the Class $\mathrm{C}$, the giving CF Class in cor $\mathrm{d}$ d senten as instructed on compound sentences for two weeks of the course period four vions. Then in the sixth session the pretest was run. In the seventh session the instry came ba with the provided CF on compound sentences for students.

They str died th feedback, or 40 minutes and then the immediate posttest was held. Then

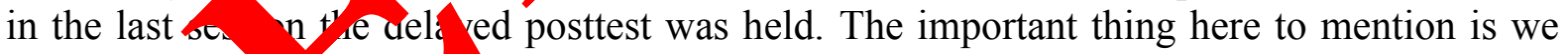
used a scale to the umber of compound sentences used by the students. The scale miniv aum as one nd the maximum was 20 use of this structure. It should be stated that dy the even ses ions in Class D the instruction was given on compound sentences. Then the $p$ nediate posttest were held in the sixth and seventh session respectively. The differen, there was No CF for students before the immediate posttest. In the last session the delaye, ${ }^{\circ}$ osttest was run.

\section{4. 3. Claim Three}

The time spent on CF may be wisely spent on additional writing practice to improve writing ability: the 20 students were placed in Class $\mathrm{E}$ in which the students just did exercises on correct verb patterns after model verbs. In the second session the pretest was held. In the third session the teacher came back but without any feedback and immediate posttest was held. During the fourth session to the last session in which the delayed posttest was run the students 
just did exercise and there wasn't any provided corrective feedback by the instructor. In the sixteenth session the delayed posttest was run. Class E was in compared with Class A, the one with $\mathrm{CF}$ on correct verb patterns after model verbs, which discussed earlier.

\section{RESULT}

After information gathered from the five classes during the two months, the following findings were emerged. Once again for the purpose of clear categorization we divided the-result section into three parts and in each part we investigated one of the research questi ons.

3. 1. Claim One: Correction may have value for non-grammatical errors by not grammatical errors.

For testing this claim, we gathered the data in Class A in whicb vas mpos d on verb patterns after model verbs and Class B in which there was No CF ner tterns a cer model verbs. The descriptive statistics of these two classes were shoy $n$ Table 1

Table 1. Descriptive statistics for means score Class A Class B.

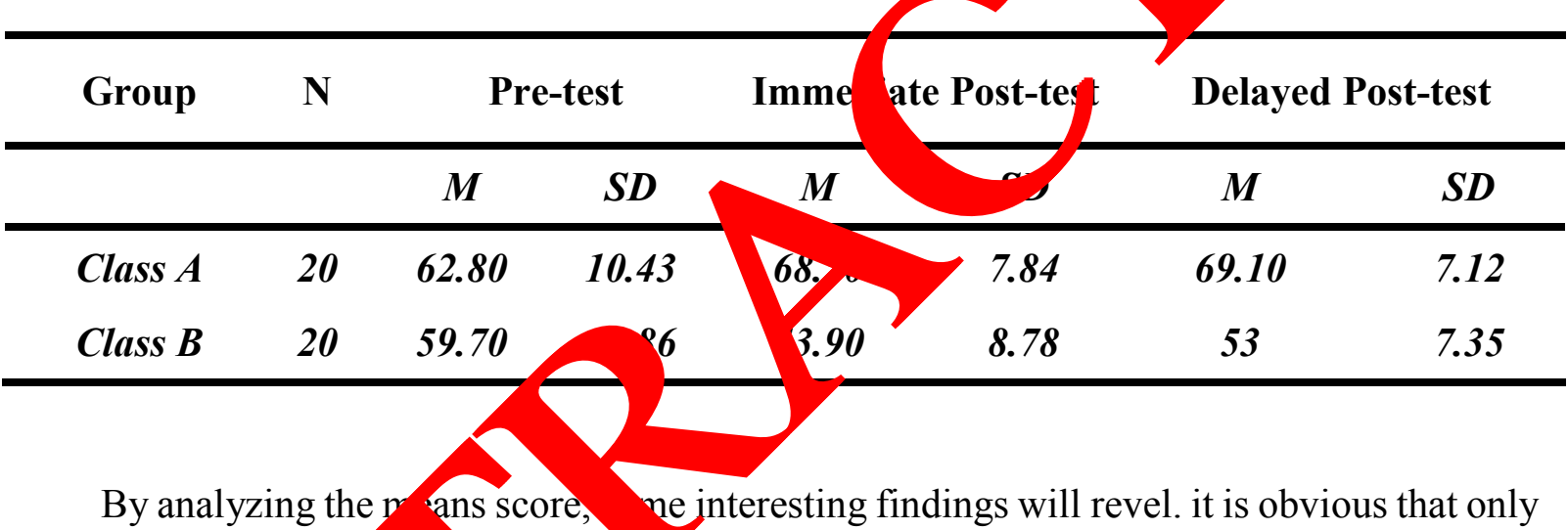

Class A which was $y$ do e impact giving CF in correct verb pattern after model verbs improve its mean acd racy a time of the immediate posttest and in the delayed posttest. It is something fro 62.80 in the rest to 69.10 in the delayed posttest.

The 67 means core increasing clearly shows the impact of giving $\mathrm{CF}$ in improving students' accu. an corre t verb pattern after model verbs. On the other hand, in Class B in which the was $\mathrm{CF}$ a correct verb pattern after model verbs the means score decreased from 59.7 $n$ the p ot to 53 in the delayed post test.

The 70 amo/nt of decreasing indicates that not giving CF to students on correct verb patten ter moud verbs caused them to lose their accuracy in this field. The $p=.049$ for the Class A. showed the effective of giving CF in Writing Class in comparison with $p=.52$ of Class B, sy the hypotheses is confirmed that giving CF to students' grammatical errors is significant. Fig. 1. and Fig. 2 also provide a visual representation of Means score of Class A and Class B during the pretest, posttest, and delayed posttest. 
Fig.1. Means Score of Class A:Giving CF on Grammatical Errors

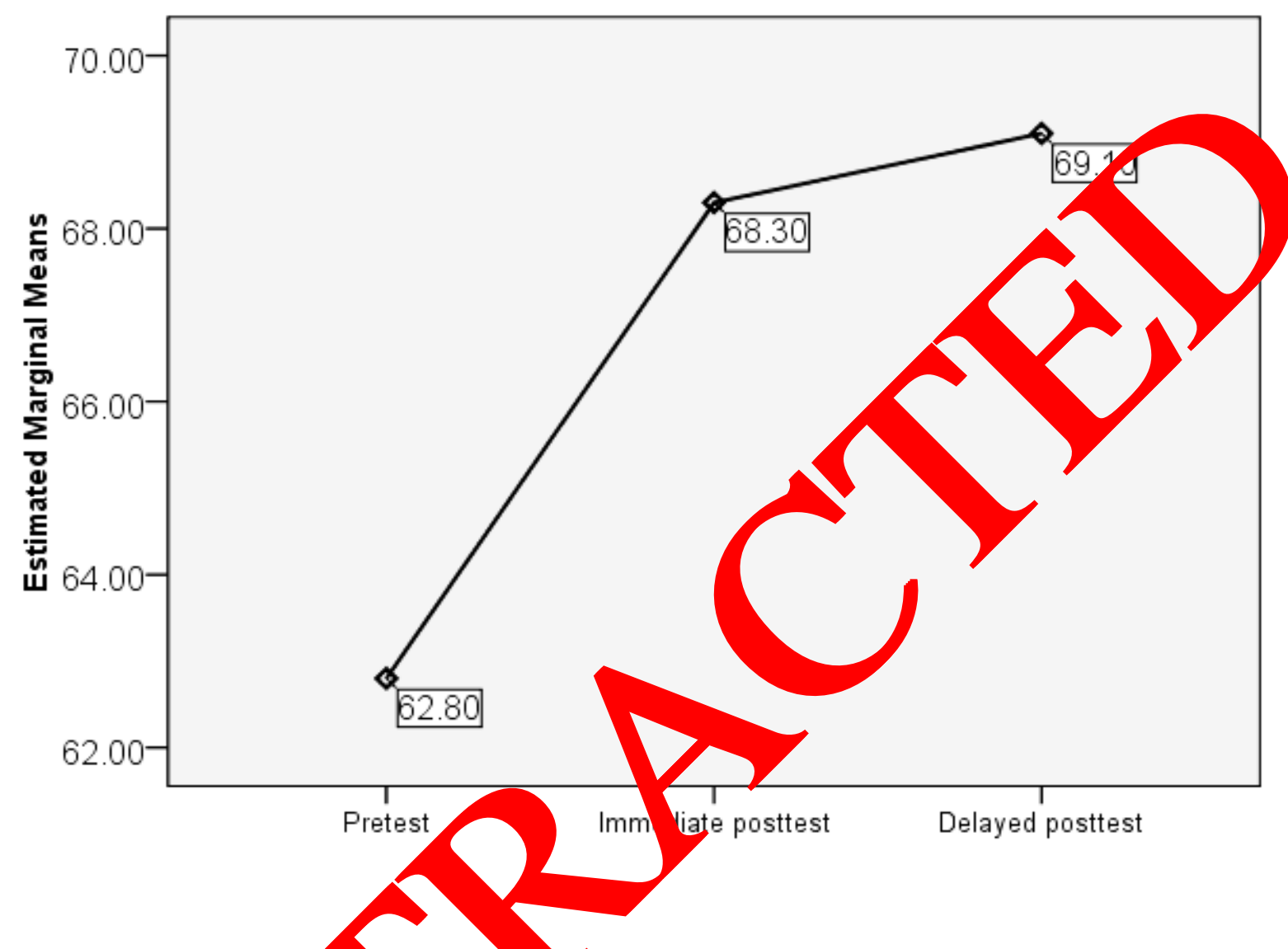

Fig. 1 illustrate tha means s ore of Class A and students' accuracy increase during the immediate poste and o ved posttest which is due to the giving of CF on correct verb pattern after mo ael verbs in tho mediate posttest.

All in and $b$ on the data achieved the first claim is going under question because it shows that, $\mathrm{CF}$ in ammatical errors improve student's accuracy in their writings. So the ans to the rese arch question is confirmed that giving CF improve their grammatical accy acy. delaye 'sttest. delaye

\section{2. Stude is are inclined to avoid more complex constructions due to giving $C F$}

Table 2 is a manifestation of the descriptive statistics of the Class C and Class D. As it was stated earlier Class $\mathrm{C}$ was going under giving $\mathrm{CF}$ in compound sentences of English in order to find out whether or not giving CF caused students' to avoid or not to avoid complex structures. 
Fig.2. Means Score of Class B: Not giving CF in Grammatical Errors

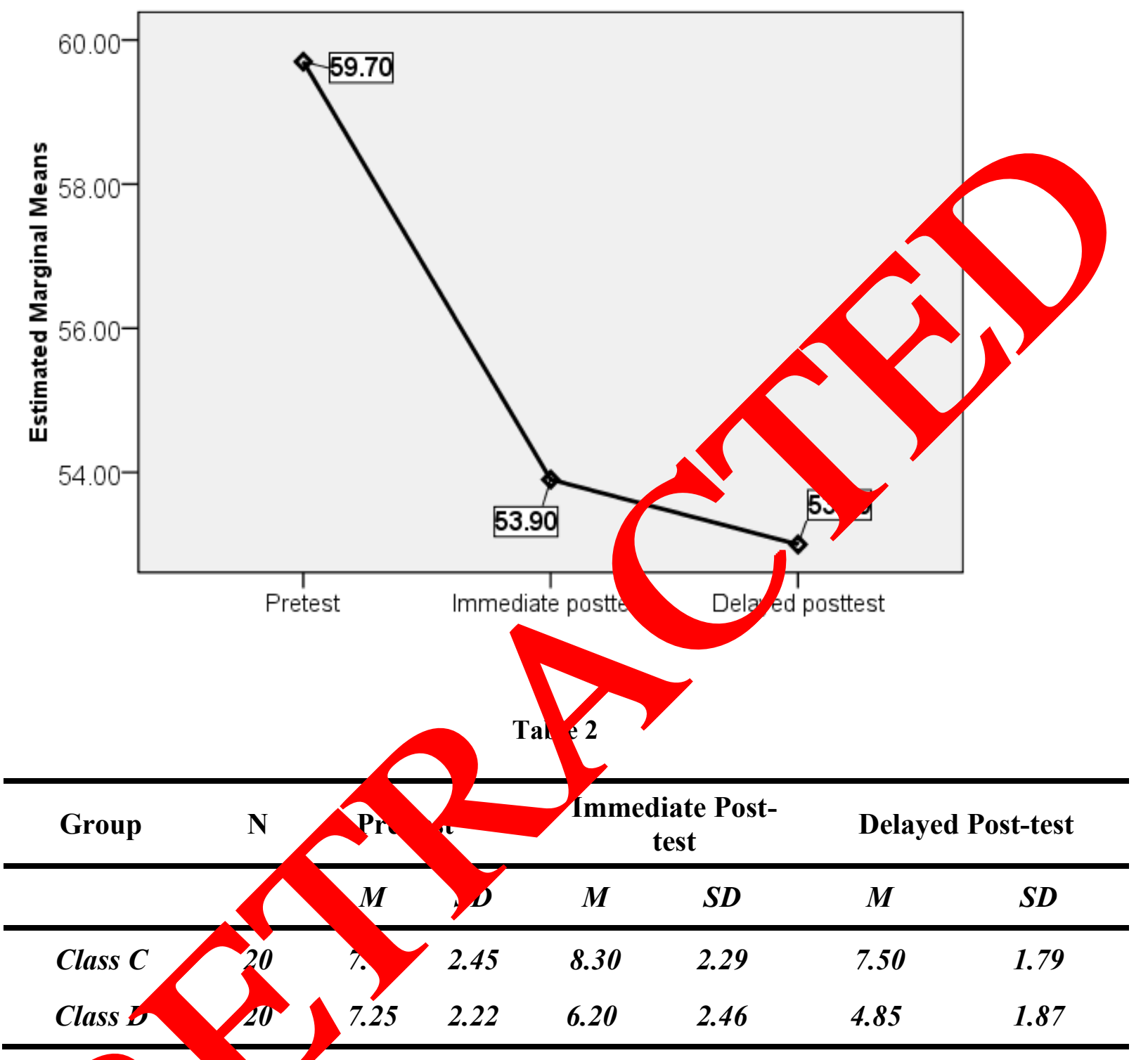

araino means score, it is cleared that Class $\mathrm{C}$ means score of using compound senten in immediate posttest was 8.30 the time when the instructor gave CF on this complex structure, $/$ as soon as the feedback stopped during the immediate posttest and delayed posttest the means score of using compound sentences was starting to decline. This finding from one side and from the other side the decreasing means score in Class D from 7.25 in pretest to 4.85 in the delayed posttest showed that not only giving CF doesn't decrease the number of using compound sentences but also giving CF increase it as it cleared in the immediate posttest of Class A. Fig. 3 and Fig. 4 also provide a visual representation of Means score of Class $\mathrm{C}$ and Class D during the pretest, posttest, and delayed posttest. 
Fig.3.Means Score of Class C: Using CF on Complex Structures

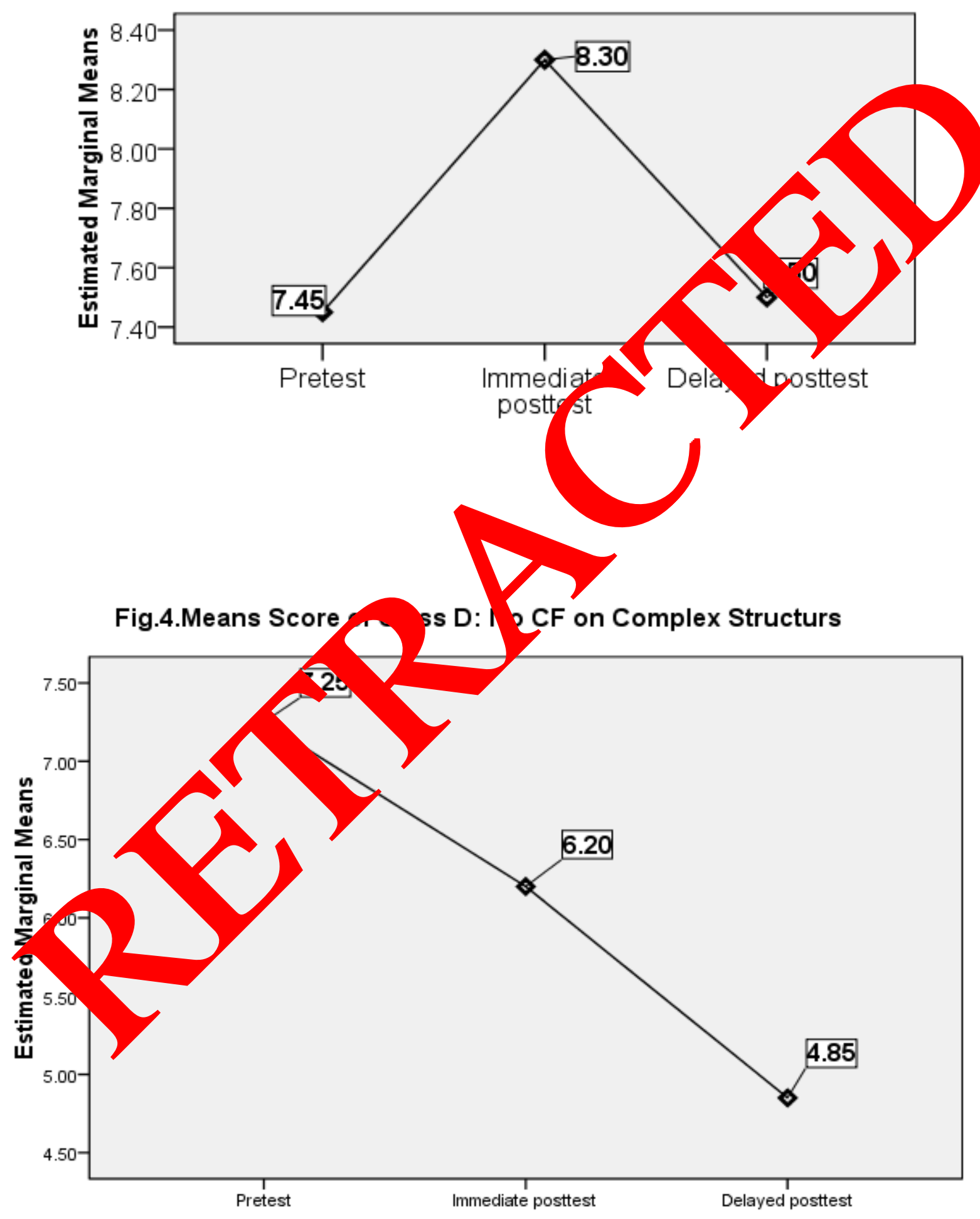


Fig. 3 shows that in the moment of giving CF on compound sentences the mean score increased to 8.30 but afterward when CF was stopped the mean score is starting to decrease and finally in the delayed posttest it reached 7.50 , yet .05 more than the pretest at the beginning of the program.

Fig.4. devoted to the means score of Class D in which students weren't given CF in compound sentences. It shows that the means score decrease during the pretest, immediate posttest and delayed posttest. The second research question isn't clear. Albeit we have seen means score increasing in Class $\mathrm{C}$ in the immediate posttest and decrease in means score in Class D during the entire of the program, there should be more experiments and resonch to reach a stable answer.

\section{3. Claim Three: The time spent on CF may be wisely spent on addition w practice to improve writing ability.}

For testing the final claim we compared the descriptive station of $C_{1}$ ass $\mathrm{K}$ in which students did just practice excursuses on correct verb patterns after mel bs and class A in which students were given $\mathrm{CF}$ on correct verb patterns after $m$ verbs. 1 comparison.

Table 3

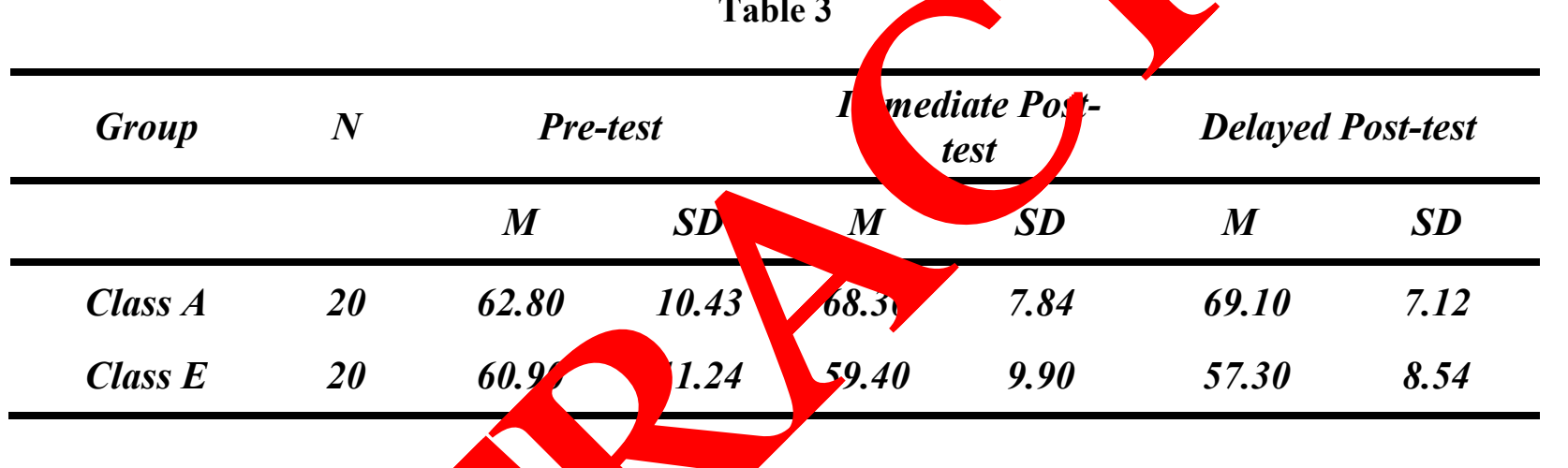

The means score 'ass E dec ed during the program, in the immediate posttest it's 59.40 while in the d ayed thest it' 57.30 . On the other hand, the mean score in the Class A increase from 00.30 in the nodiate posttest to 69.10 in the delayed posttest. The results shows that gi ng CH on correct, erb patterns after model verbs has a better effect than just do exercises on ree verb atterns after model verbs. The $p=.52$ for Class E showed the rejection of the othese that spending time on doing exercises may improve the students' writy a ty mu re than giving CF. on the other hand, $p=.049$ of Class A confirmed ag that Iving CF ras significant effect on students' writing accuracy.

g. 6 also provide a visual representation of Means score of Class A and Class

E during e pretest, posttest, and delayed posttest. Fig. 5 illustrates that the means score of Class A an students' accuracy increase during the immediate posttest and delayed posttest which is due to the giving of CF on correct verb pattern after model verbs in the immediate posttest. Fig. 6 shows that the means score of Class $\mathrm{E}$ decrease during the immediate posttest and in the delayed posttest. It shows that the claim that not giving CF and just do exercise is all due to question. The findings indicate that the third research question is not confirmed and there should be amount of CF in writing Classes and just doing exercises in the class isn't enough. 
Fig.5. Means Score of Class A:Giving CF on Grammatical Errors

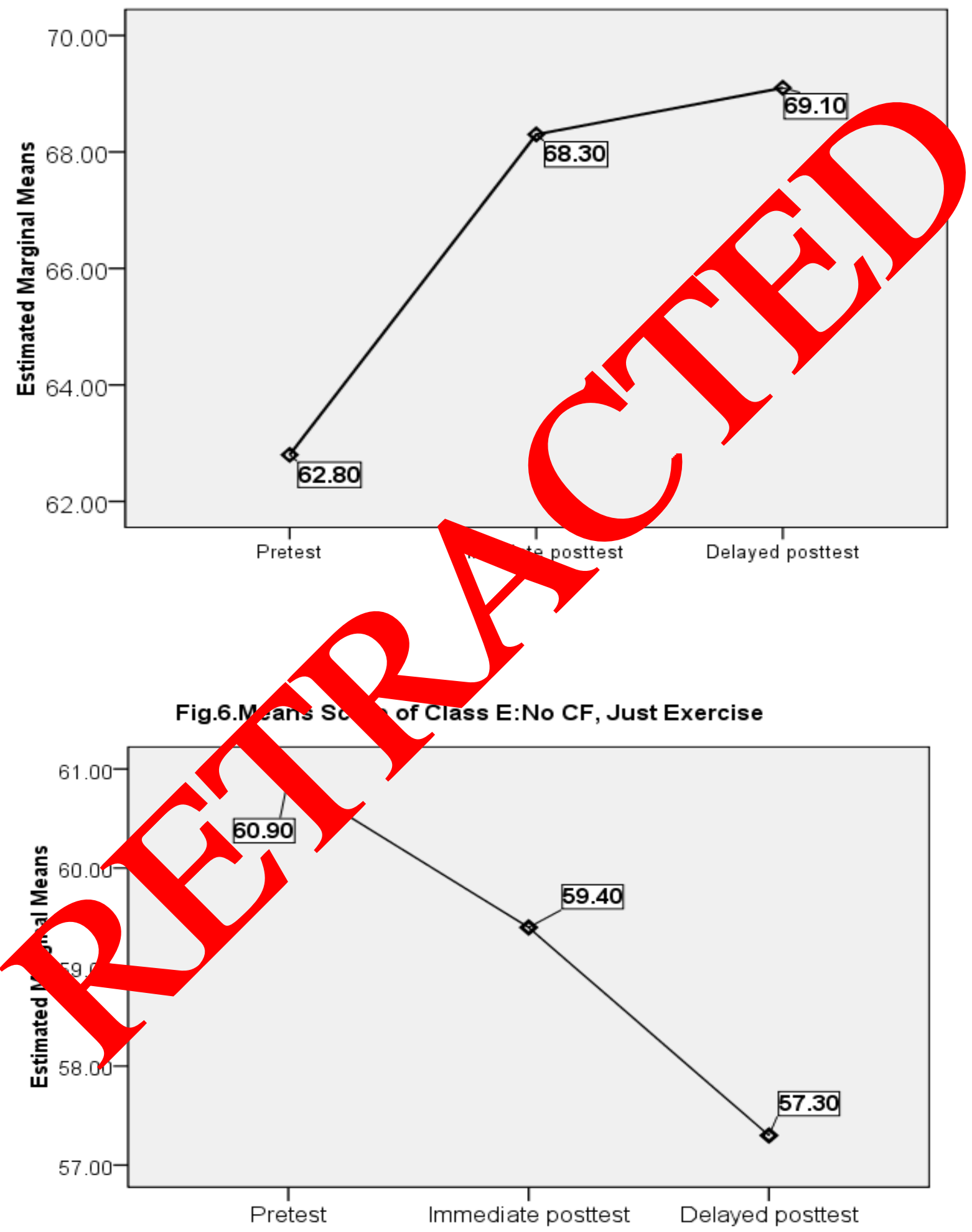




\section{CONCLUSION}

As it was stated earlier the purpose of this research was to investigate Truscott's claim in giving CF to students' writings. The findings of this study were in accordance with those done researches in which giving CF increase the accuracy of students' writings (Fathman \& Whalley, 1990; Ferris, 1997; Ferris \& Roberts, 2001; Bitchener, 2008; Bitchener \& Knoch, 2008, 2009, 2010a, 2010b; Ellis, Sheen, Murakami, \& Takashima, 2008; Sheen, 2007, 2010).

It was found that unlike what Truscott claimed about giving CF to grammatical errors that would be useless, it is not and surely giving CF to students' grammatical errome will improve their accuracy in their writings. The research also indicated that as far as cachers $\mathrm{CF}$ on complex structures like compound sentences the students not only $\mathrm{d}$ inclined avoid but also they inclined to use these structure much more in the momen of $g$, CF. $\mathrm{C}$ one another perspective the results show that in comparison with giving $C F$ to a gra nat point, doing just exercises on a specific grammatical point has less eff - So t claim at the time spent on CF may be wisely spent on additional writing practic to ve writ gability is due to big doubt.

Overall, the results show that students can be able to writing classrooms. This CF may be imposed on grammatica erron non-grammatical errors (Bitchener, 2008; Sheen, 2007). It is important to note man this st we worked on EFL students and further research may be required to oth situation. The stadents involved in this research study were all advanced in English profici cy and there also required other level of proficiency to work on in order to see the result them. Tb grammatical point is also restricted in this research study. We make yed of corn patterns after model verbs and other researches may benefit from other gra points. A pedagogical implication of the findings of the study for giving corrective fee $\mathrm{bac}^{\prime}-\mathcal{L}$ contexts is that giving CF provides students with an excellent mean to imnrove the writing accuracy. For doing this, teachers can give a report on the students wri ngs which i dicate the problematic part for the students.

\section{References}

[1] Ashwell, T.(2 0 o. Patto of teacher response to student writing in a multiple-draft compositic a classroom: Is atent feedback followed by for $m$ feedback the best method? vurna Second Language Writing, 9, 227-258.

[2] Beglar, D., Junt, $\mathrm{H}$ (1999). Revising and validating the 2000 word level and yit ty wo 1 vocabulary tests. Language Testing, 16, 131-162.

[3] tch or I (2008). Evidence in support of written corrective feedback. Journal of Sa vallangage Writing, 17, 102-118

[4] Bitch Y, J., Young, S., \& Cameron, D. (2005). The effect of different types of corrective feedback on ESL student writing. Journal of Second Language Writing, $14,227-258$.

[5] Broekkamp, H., Van Hout-Wolters, H., Van den Bergh, H., \& Rijlaarsdam, G. (2004). Teachers' task demands, students' test expectations, and actual test content. British Journal of Educational Psychology, 74, 205-220.

[6] Bruton, A. (2009). Designing research into the effect of error correction in L 2 writing: Not so straightforward. Journal of Second Language Writing, 18, 136-140. 
[7] Chandler, J. ( 2003). The efficacy of various kinds of error feedback for improvement in the accuracy and fluency of L2 stuudent writing. Journal of Second Language Writing, $12,267-296$.

[8] Cohen, J. (1988) Statistical power analysis for the behavioral sciences (2 ${ }^{\text {nd }}$ ed.). Hillsdale, NJ: Erlbaum.

[9] DeKeyser, R. M. (2003). Implicit and explicit learning. In C. J. Doughty \& M. H. Long (Eds.), Handbook of second language acquisition (pp. 313-348). Oxford: Blackwell.

[10] Ellis, R. ( 2004). The definition and measurement of L2 explicit knowledge. I Learning, 54, 227-275.

[11] Fathman, A., \& Whalley, E. (1990). Teacher response to student writing: 1 s on for versus content. In B. Kroll ( Ed.), Second language writing: Researc insight classroom (pp. 178-190). Cambridge: Cambridge University Pre

[12] Ferris, D. (1995). Teaching ESL composition students to bec endent dfeditors. TESOL Journal, 4, 18-22.

[13] Ferris, D. (1997). The impact of teacher commentary Quarterly, 31, 315-339.

[14] Guenette, D. (2007). Is feedback pedagogically orrect? Research design issues in studies of feedback on writing. Journal of Sec d Language Writing, 16, 40-53.

[15] Guiraud, H. (1954). Lescaract 'eres statistiques vocabu aire. Paris: Presses Universitaires de France.

[16] Hartshorn, K. J., Evans, N. W., Merrill, F F ceks, R. R., Strong-Krause, D., \& Anderson, N. J. (2010). Effects-of dynan corrective feedback on ESL writing accuracy. TESOL Quarterl , 44, 4-109.

[17] Li, S. (2010). The effearn ss feedback in SLA: A meta-analysis. Language Learning 00.009

[18] Loewen, S . (20 4). take in in cental focus on for $m$ in meaning-focused E SL lessons. Lanouv re Le. ing, 54,153-188.

[19] Lyster, $\mathrm{B}, 200^{4}$. Differe effects of prompts and recasts in form-focused instruction. Studie Sece con La guage Acquisition, 26, 399-432.

[20] Lycter, R., aito (2010). Oral feedback in classroom SLA: A meta-analysis.

stum in Sec Language Acquisition, 32, 265-302.

[21] B. (2000). The CHILDES project: Tools for analyzing talk. Mahwah, NJ: b 9um.

[22] Norr, J. M ., \& Ortega, L. (2009). Towards an organic approach to investigating CAF in instructed SLA: The case of complexity. Applied Linguistics, 30, 555-578.

[23] Sheen, Y. (2010). Differential eff ects of oral and written corrective feedback in the ESL classroom. Studies in Second Language Acquisition, 32, 201-234.

[24] Sheen, Y., Wright, D., \& Moldawa, A. (2009). Differential effects of focused and unfocused written correction on the accurate use of grammatical for ms by adult ESL learners. System, 37, 556-569. 
[25] Sheppard, K. (1992). Two feedback types: Do they make a difference? RELC Journal, $23,103-110$.

[26] Skehan, P. (1998). A cognitive approach to language learning. Oxford: Oxford University Press.

[27] Skehan, P., \& Foster, P. (2001). Cognition and tasks. In P. Robinson (Ed.), Cognition and second language instruction (pp. 183-205). Cambridge: Cambridge University Press.

[28] Truscott, J. (2007). The effect of error correction on learners' ability to write a Journal of Second Language Writing, 16, 255-272.

[29] Truscott, J. (2010). Some thoughts on Anthony Bruton's critique of the con tion debate. System, 38, 329-335.

[30] Truscott, J., \& Hsu, A. Y. -p. ( 2008). Error correction, revision d lear g. Jov hal of Second Language Writing, 17, 292-305.

[31] Van Beuningen, C. G., De Jong, N. H., \& Kuiken, F. (20 The effec Srect and indirect corrective feedback on L2 learners' written as arac, 'TL International Journal of Applied Linguistics, 156, 279-296.

[32] Van Eerde, H. A. A., \& Hajer, M . (2005). Lar uage sensitive msthematics teachingStudents' talking and writing enlighten hidden roblems. In M. Bosch, (Ed.), Proceedings of the Fourth Congress of the Eur an Societ for Research in Mathematics Education (pp. 1215-1225). Sant Fo a'1xols, Spain: Fundemi IQSUniversitat $\mathrm{R}$ amon Llull.

[33] Wolfe Quintero, K., Inagaki, S ., \& Kim, H Y. ( ,98). Second language development in writing: Measures of flue curacy and syntactic complexity. Honolulu: National Foreign Language Resou e Cen r.

[34] Xu, C . (2009). Over era narrow focus: A response to Ellis et al. (2008) and Bitche (2008). rngl of Second Language Writing, 18, 270-275.

[35] Zareva, A., Sc anè gel, P., \& Nikolova, Y. ( 2005). Relationship between lexical competenc and langua roficiency. Studies in Second Language Acquisition, 27, 567-595 